\title{
Aspiration and methylprednisolone injection to the cavity with IV cannula needle in the treatment of volar wrist ganglia
}

\author{
Jain S. ${ }^{1}$, Gupta D.K. ${ }^{2}$, Jain M. ${ }^{3}$ \\ ${ }^{1}$ Dr. Sidharth Jain, Resident, ${ }^{2}$ Dr. Dinesh Chand Gupta, Resident, ${ }^{3}$ Dr. Mudit Jain, Resident; all authors are attached with \\ Gandhi Medical College Bhopal.
}

Corresponding Author: Dr. Sidharth Jain, Resident, Gandhi Medical College Bhopal, Email: dr.sidrjain@gmail.com

\begin{abstract}
Objective: There are several types of treatment modalities recommended for wrist ganglions. The purpose of this study was to evaluate the effectiveness of cyst aspiration and methyl prednisolone acetate injection by using double IV cannula, as a new technique involar ganglia treatment. Methodology: The study involves total of 24 patients who received treatment by aspiration and methyl prednisolone injection into the cavity. Two IV cannulas are pricked to the cystic cavity. Cyst fluid is drained by the distally placed IV cannula meanwhile injecting methyl prednisolone by proximally placed IV cannula. The patient records and follow-up reports are retrospectively investigated. The patient age, sex, site of the cyst, the treatment that was applied, adjacency to the artery and the nerves and recurrence are recorded. Results: The study involved 24 patients that received aspiration treatment for volar ganglion cysts between June 2011 and July 2014. Patients mean follow up time was $2.4 \pm 0.2$ years. There were $16(63.3 \%)$ female and $8(36.6 \%)$ male subject with volar wrist ganglia. The mean age of the patients was $30.63 \pm 6.8$ years. This study didn't reportany complication related to methyl prednisolone injection and arterial ischemia. Recurrence was observed in 4 (16.6\%) patients. Conclusion: This method is found to be associated with lower recurrence rate than other aspiration therapy. We highly recommend to use IV cannula needle for ganglionic cyst aspiration and methyl prednisolone injection in treatment of volar ganglia prior to any surgical intervention.
\end{abstract}

Keywords: Aspiration; Radial artery; Volar; Wrist ganglia

\section{Introduction}

Ganglion is one of the common cystic lesion. It is benign, fluid-filled capsule which can appear around any joint of the body [1]. The ganglia can originate from the joint capsule, tendon, tendon sheath and very rarely from the arterial wall [2,3]. Ganglionic cysts usually develop in the consequence of fluid leak out where placed within the sheath that surrounds thetendons. It develops in to a cystic structure that contains fluid which is identical to normal joint fluid.

Ganglionic cyst around wrist jointare commonly observed in the dorsal aspect and less commonly in the volar aspect [2]. A pedicle can communicate cyst with the joint Ganglia are found commonly in women than in men. They are often appear inthird and the sixth decades of life [4]. Common size ranges from 1 to $3 \mathrm{~cm}$ diameter butsome case reports stating larger diameter of ganglia. Most of the patients remain asymptomatic

\footnotetext{
Manuscript Received: $9^{\text {th }}$ June 2018

Reviewed: $18^{\text {th }}$ June 2018

Author Corrected: $26^{\text {th }}$ June 2018

Accepted for Publication: $30^{\text {th }}$ June 2018
}

sometime the pain appear when the cyst applies pressure on adjacent soft tissues, especially on a nerve. Sometimes volar ganglionic cyst may cause paresthesia due to compression of ulnar or radial nerves or their branches. The swelling is generally smooth, fairly tense and fixed. Common ways of treatment of ganglia; 1) Conservative therapyfor small sized, asymptomatic lumps, 2) Aspiration 3) Surgical excision. Aspiration is commonly performed via single or double sharp pointed needle. Cyst fluid aspiration is followed by steroid injected into cyst cavity. The reported recurrence rate for above techniques is relatively high, $59 \%$ - $68 \%$ for dorsal ganglion, even higher recurrence rate of $88 \%$ for volar ganglion $[5,6]$.

The current study was formulated to evaluate the effectiveness of ganglionic cyst aspiration and methyl prednisolone acetate injection infusion with double IV cannula, as a new technique in the treatment ofganglia of volar aspect of wrist. 


\section{Original Research Article}

\section{Methodology}

This Prospective clinical trial was conducted in Gandhi medical college Bhopal after appropriate clearance between June 2011 and July 2014. Inclusion criteria was patient with volar wrist ganglion in 16 to 60 year of age. In this study 24 patients were included having volar wrist ganglion were. Patient with dorsal wrist ganglion and concomitantly having other pathology around wrist joint were excluded. Age limit was 16 to 60 years. After proper consent these patients have received treatment by aspiration and methyl prednisolone acetate injection for volar ganglion cysts between January 2011 and December 2016.

The patient information and follow-up findings were evaluated. The patient age, sex, cyst location, adjacency to the neuro vascular structures, recurrences and complications were recorded. Patients were followed by clinical examination and ultrasonography for the period of two years after the cyst aspiration. Cysts were evaluated for diameter, tenderness and characteristic of the cystic fluid by clinical and ultrasound testing. Two IV cannulas were inserted to the cystic cavity; one of the IV cannula size of 18 Gauge $(G)$ tip was pricked distal part of the cyst for evacuation of the cavity. At the proximal part of the cystanother $18 \mathrm{G} \mathrm{IV} \mathrm{cannula} \mathrm{was}$ inserted to inject methyl prednisolone into the cyst cavity. Of two IV cannulas, the metal parts were removed, only plastic parts remained inside cystic cavity. Evacuation ofthe cavity by IV cannula from the distal part, and infusion of methyl prednisolone (DepoMedrol®, $40 \mathrm{mg}$ methyl prednisolone) via the IV cannula at the proximal part were performed simultaneously.

This process continued until all cystic fluid was drained completely and white colored methyl prednisolone became visible in the needle that placed distally. Patients were followed up biweekly for one month then once in every two months for two years. Patients were asked about symptomatic relief and increase in their functional performance. In follow up patients were examined clinically for recurrence also. Difference between male and female in terms of recurrence was insignificant (Fisher's exact test).

\section{Results}

Patients mean follow up time was $2.4 \pm 0.2$ years. There were $16(63.3 \%)$ female and $8(36.6 \%)$ male subject with volar wrist ganglia. The mean age of the patients was $30.63 \pm 6.8$ years. All the cysts were smaller from 3 centimeter $(\mathrm{cm})$ diameter. Of ganglia $16(63.3 \%)$ were in right hand and $8(36.6 \%)$ were in left hand. The cysts near in proximity to the radial artery were detected in $16(63.3 \%)$ patients by ultra sonography. Any complication related to methyl prednisolone acetate injection was not reported. $4(15.8 \%)$ patients showed recurrence in follow up. difference between male and female in terms of recurrence was insignificant (Fisher's exact test, $\mathrm{p}=0.7$ ). The recurrent ganglion cysts were finally treated by surgical excision.

Table-1: Demographic and clinical data.

\begin{tabular}{|c|c|}
\hline Male / Female (n) (\%) & $8(36.6) / 16(63.3)$ \\
\hline Age, mean \pm S.D. (years) & $27.63 \pm 6.6$ \\
\hline Mean follow-up time, mean \pm S.D. (years) & $2.4 \pm 0.2$ \\
\hline Recurrence (n) (\%) & $3(15.8)$ \\
\hline Side of wrist Right/left (n) (\%) & $16(63.3) / 8(36.6)$ \\
\hline Adjacency arteries and nerves $+/-(\mathrm{n})(\%)$ & $15(62.5) / 9(37.5)$ \\
\hline
\end{tabular}

SD: standard deviation

\section{Discussion}

Ganglion is one of the common cause of a palpable mass in the wrist and hand. [7,8] Various treatment available; observation, aspiration, aspiration along with sclerotherapy, arthroscopic excesion and surgical excision. In this study, we have achieved expected results with ganglionic cyst aspiration andmethyl prednisolone acetate injection treatment with IV cannula needle in patients having volar wrist ganglia. In follow-up period of this new aspiration technique with plastic IV cannula needle, we found in our study that this technique is associated with less complication, low recurrence rate and decreased need for surgical excision. Various treatment modalities with different complication rates are reported. Faithfull et al showed 


\section{Original Research Article}

that in $28 \%$ of patients who have undergone surgical excesion were not satisfied due to persistent pain, limitation of activity [9]. Gundes et al. reported the complication rate was $56 \%$ for volar ganglia and $12.5 \%$ for dorsal ganglia. They reported injury to palmar cutaneous branch of the median nerve in two patients and laceration of the palmar superficial branch of the radial artery in two patients [10]. Ananother study reported injury to the median palmar cutaneous nerve in $10 \%$, injury to the radial artery in $5 \%$ and wrist stiffness in $12.5 \%$ of the patients. [11] In an another study comparableresults were obtained [12].

Gumus et al. reported that sclera therapy can damages the lining of the main ganglionic cyst and causes severe fibrosis around the cyst. [13] Some other studies have reported is chemia of index finger and thumb after aspiration and sclerosing agent injection in volar wrist ganglion. in such cases if palmar circulation did not recover it can lead to gangrene with clear demarcation. The patients distal phalanx of left thumb had to be amputated [14]. Some other animal study explains the inherent complications of this therapy with radiological and electron microscopic data [15]. This aspiration technique with plastic IV cannula needle associated with no nerve-arterial damage or limitation of movement in wrist.

Surgical and arthroscopic excision for volar wrist ganglion are associated with recurrence between 14$28 \%$ in the literature $[9,16,17]$. In some previous studies, recurrence rates of ganglion cyst after simple aspiration and aspiration plus steroid injection therapies were $59-68 \%$ and $40 \%$ respectively $[6,18]$. In the current study we found the recurrence rate of $15.8 \%$. Therecurrence rate of this method is quite lower than the one with other method using sharp pointed needle. Even this low recurrence rate in current study is comparable with the recurrence rates of surgical and arthroscopic excision.

Arthroscopic resection is also newly developed technique. in this technique after the operation there was minimal impairment of wrist motion, function and neurovascular damage. [19,20] Few recent studies have suggested that for arthroscopic resection of dorsal wrist ganglion is an effective and safe method with minimal post operative morbidity and better cosmetic results. But they have also advised that volar ganglia should preferably be treated by open operation because arthroscopic excision is technically demanding surgery $[21,22]$. The use of IV cannulas enables direct approach inside the ganglionic cyst. After identifying the clear cystic fluid coming out from the IV cannula, sharp metalic part is removed out, as plastic part is less harmful for adjacent artery and nerves. Therefore chances of injury to adjacent structures are very less. The cause of low recurrence rate in this study is near complete aspiration of the cystic fluid until the white colored methyl prednisolone acetate is seen coming out from syringe.

\section{Conclusion}

In conclusion, in thus study we have evaluated the new method of treatment of ganglionic cyst by aspiration and simultaneous injection of methyl prednisolone acetate into the cavity by IV cannula needle. This method is having lower recurrence rate as compare to other aspiration therapy.

We recommend use of this simple method of treatment of Intra Venous cannula needle for cyst aspiration and steroid injection forvolarwristganglia before any surgical intervention, as this method is simple, effective, minimallyinvasive andsafe. As per demand of Indian patient this procedure is a minor surgical procedure which can be done in day care also avoiding anesthesia side effect in patient having systemic comorbidities.

Conflict of interest: None declared.

\section{Funding: Nil, Permission from IRB: Yes}

\section{References}

1. Nahra ME, Bucchieri JS. Ganglion cysts and other tumor related conditions of the hand and wrist. DOI: 10 . 1016/j.hcl.2004.03.015

2. Nelson CL, Sawmiller S, Phalen GS. Ganglions of the wrist and hand. J Bone Joint Surg Am. 1972 Oct;54 (7):1459-64.

3. Burke FD, Melikyan EY, Bradley MJ, Dias JJ. Primary care referral protocol for wrist ganglia. Postgrad Med J. 2003 Jun;79(932):329-31.

4. Thommasen HV, Johnston S, Thommasen A. Management of the occasional wrist ganglion. Can J Rural Med. 2006 Winter;11(1):51-2.

5. Nield DV, Evans DM. Aspiration of ganglia. J Hand Surg Br. 1986 Jun;11(2):264.

6. Richman JA, Gelberman RH, Engber WD, et al. Ganglions of the wrist and digits: results of treatment by aspiration and cyst wall puncture. J Hand Surg Am. 1987 Nov;12(6):1041-3. 
7. TehJ, Whiteley G. MRI of soft tissue masses of the hand and wrist. DOI:10.1259/bjr/53596176

8. Thornburg LEGanglions of the hand and wrist. J Am Acad Orthop Surg. 1999 Jul-Aug;7(4):231-8.

9. Faithfull DK, Seeto BG. The simple wrist ganglion-more than a minor surgical procedure? Hand Surg. 2000 Dec; 5(2):139-43.

10. Gündeş H, Cirpici Y, Sarlak A, Müezzinoglu S. Prognosis of wrist ganglion operations. Acta Orthop Belg. 2000 Oct;66(4):363-7.

11. Aydin A, Kabakaş F, Erer M, et al. [Surgical treatment of volar wrist ganglia]. Acta Orthop Traumatol Turc. 2003;37(4):309-12.

12. Edwards SG, Johansen JA. Prospective outcomes and associations of wrist ganglion cysts resected arthroscopically. DOI:10.1016/j.jhsa.2008.11.025

13. Gümüş N. A new sclerotherapy technique for the wrist ganglion: transcutaneous electro cauterization. DOI: $10.1097 /$ SAP.0b013e31818a664f

14. Jalul M, Humphrey AR. Radial artery injury caused by a sclerosant injected into a palmar wrist ganglion. DOI:10.1177/1753193409105561

15. Mackie IG, Howard CB, Wilkins P. The dangers of sclerotherapy in the treatment of ganglia. J Hand Surg Br. 1984 Jun; 9(2):181-4.

\section{Original Research Article}

16. Jacobs LG, Govaers KJ. The volar wrist ganglion: just a simple cyst? J Hand Surg Br. 1990 Aug;15 (3) : 342-6.

17. Ho PC, Griffiths J, Lo WN, et al. Current treatment of ganglion of the wrist. Hand Surg. 2001Jul; 6 (1): 49-58.

18. Holm PC, Pandey SD. Treatment of ganglia of the hand and wrist with aspiration and injection of hydrocortisone. Hand. 1973 Feb;5(1):63-8.

19. Ho PC, Law BK, Hung LK. Arthroscopic volar wrist ganglionectomy. Chir Main. 2006; 25 (S1): 221-230.

20. Ho PC, Lo WN, Hung LK. Arthroscopic resection of volar ganglion of the wrist: A new technique. DOI: 10. 1053 jars. 2003.50035

21. Rocchi L, Canal A, Pelaez J, et al. Results and complications in dorsal and volar wrist Ganglia arthroscopic resection. DOI:10.1142/S0218810 40600 3127.

22. Rocchi L, Canal A, Fanfani F, Catalano F. Articular ganglia of the volar aspect of the wrist: arthroscopic resection compared with open excision. A prospective randomised study. DOI:10.1080/ 0284431 0802210897

\section{How to cite this article?}

Jain S, Gupta D.K, Jain M. Aspiration and methylprednisolone injection to the cavity with IV cannula needle in the treatment of volar wrist ganglia. Surgical Update: Int J surg Orthopedics.2018;4(2):8386.doi:10.17511/ijoso.2018.i02.04. 